\title{
BubRI as a prognostic marker for recurrence-free survival rates in epithelial ovarian cancers
}

\author{
Y-K Lee ${ }^{1,2}$, E Choi', MA Kim³, P-G Park', N-H Park' and H Lee*,I \\ 'Department of Biological Sciences and Research Center for Functional Cellulomics, College of Natural Science, Seoul National University, San 56-I, \\ Shinlim-dong, Gwanak-ku, Seoul I 5 I-742, Republic of Korea; ${ }^{2}$ Department of Obstetrics and Gynecology, College of Medicine, Seoul National University, \\ Seoul, Republic of Korea; ${ }^{3}$ Department of Pathology, College of Medicine, Seoul National University, Seoul, Republic of Korea
}

BACKGROUND: Epithelial ovarian cancer is one of the most lethal malignancies, and has a high recurrence rate. Thus, prognostic markers for recurrence are crucial for the care of ovarian cancer. As ovarian cancers frequently exhibit chromosome instability, we aimed at assessing the prognostic significance of two key mitotic kinases, BubRI and Aurora A.

METHODS: We analysed paraffin-embedded tissue sections from 160 ovarian cancer patients whose clinical outcomes had been tracked after first-line treatment.

RESULTS: The median recurrence-free survival in patients with a positive and negative expression of BubRI was 27 and 83 months, respectively $(P<0.001)$. A positive BubRI expression was also associated with advanced stage, serous histology and high grade. In contrast, Aurora A immunostaining did not correlate with any of the clinical parameters analysed.

CONCLUSION: BubRI, but not Aurora A, is a prognostic marker for recurrence-free survival rates in epithelial ovarian cancers. British Journal of Cancer (2009) I 0 I, 504-5 I0. doi:I0.1038/sj.bjc.6605 I6I www.bjcancer.com

Published online 14 July 2009

(C) 2009 Cancer Research UK

Keywords: BubRI; Aurora A; ovarian neoplasm; prognosis; recurrence-free survival

Epithelial ovarian cancer is a highly lethal malignancy (Jemal et al, 2007). Although cytoreductive surgery, followed by adjuvant chemotherapy, enhances clinical responses in the majority of ovarian cancer patients, many of them experience a recurrence of disease and eventually die from resistance to chemotherapy (Kristensen and Trope, 1997). Previous studies have reported clinicopathological prognostic parameters for ovarian cancer including stage, grade, remnant of disease, and presence of ascites (NIH Consensus Conference, 1995). However, these factors have limitations in that they fail to predict the chances of survival for individual patients. Biological behaviour of the tumour, response to chemotherapy, and survival of patients vary even among clinically similar cases (Friedlander, 1998). Thus, the identification of individual prognostic factors, such as molecular markers, is required for predicting disease outcome and choice of treatment.

Chromosome instability (CIN), characterised by aneuploidy and spontaneous chromosome aberrations, is a hallmark of aggressive cancers (Sen, 2000). It is noteworthy that aneuploidy is an important feature in ovarian cancers (But and Gorisek, 2000; Shridhar et al, 2001; Gorringe et al, 2005). Therefore, understanding the basic mechanisms that lead to aneuploidy in ovarian cancer is crucial in determining the appropriate course of treatment.

Aneuploidy can result from inaccurate chromosome segregation, dysregulated centrosome cycles, or improper cytokinesis (Chi and Jeang, 2007). Therefore, the spindle assembly checkpoint

* Correspondence: H Lee; E-mail: HL2I2@snu.ac.kr

Received 13 January 2009; revised I June 2009; accepted 5 June 2009; published online 14 July 2009
(SAC), which ensures that all chromosomes are attached to bipolar spindles and that sister chromatid separation occurs accurately, has a crucial function in genetic integrity. Impaired SAC function has been suggested to be one of the causes of aneuploidy in human cancers (Cahill et al, 1998; Amon, 1999). Among the SAC components, BubR1 mitotic kinase, known as BUB1B by the Human Genome Organization, attracts a lot of attention because it is central in the inhibition of Anaphase promoting complex/ cyclosome (APC/C) (Tang et al, 2001; Yu, 2002; Chan and Yen, 2003; Choi et al, 2009). Furthermore, BubR1 monitors kinetochore-microtubule attachments and has a pivotal function in checkpoint signaling (Abrieu et al, 2000; Lampson and Kapoor, 2005; Elowe et al, 2007).

An accurate centrosome number and organisation is critical in the equal segregation of chromosomes to daughter cells during mitosis. Indeed, centrosome aberrations have been observed in many cancers (Nigg, 2002, 2006). Aurora A kinase is particularly important for centrosome regulation because it is required for the maturation of centrosomes during mitosis (Hannak et al, 2001; Berdnik and Knoblich, 2002). Notably, the overexpression or amplification of Aurora A kinase has been found to occur in many human cancers (Zhou et al, 1998; Sen et al, 2002, 2008; Tong et al, 2004), and thus has been suggested to provoke aneuploidy and tumourigenesis (Sen et al, 2002, 2008; Tong et al, 2004). Although overexpression of Aurora A is clearly responsible for aneuploidy, whether it induces carcinogenesis is not clear (Anand et al, 2003; Zhang et al, 2004; Giet et al, 2005).

In this study, we investigated whether BubR1 or Aurora A levels can be used as prognostic markers for ovarian cancers. 


\section{MATERIALS AND METHODS}

\section{Cell culture of ovarian cancer cell lines and primary ovarian cancers}

Human ovarian cancer cell lines, OVCAR3, SK-OV-3, and SNU119, were obtained from the Korean Cell Line Bank and grown in monolayer cultures in RPMI 1640 supplemented with fetal bovine serum $(10 \% \mathrm{v} / \mathrm{v})$.

Primary ovarian cancer samples were collected from the Seoul National University Hospital from patients undergoing cytoreductive surgery. Tumour tissue was dissected into a $100 \mathrm{~mm}$ Petri dish containing serum-free RPMI medium supplemented with trypsin. After $30 \mathrm{~min}$ at $37^{\circ} \mathrm{C}$, the cells were resuspended and maintained in RPMI 1640 supplemented with fetal bovine serum (10\% v/v).

\section{Patients and tissue samples}

Tissue specimens for immunohistochemistry were obtained from 160 epithelial ovarian carcinomas by primary cytoreductive surgery between 1998 and 2005. All samples were taken from primary ovarian lesions in each patient. The disease stage of each sample was determined according to the International Federation of Gynecology and Obstetrics (FIGO) criteria. Of the patients, 82 experienced a relapse and 37 died of ovarian cancer. Ten normal ovarian tissue samples were obtained as controls. Formalin-fixed, paraffinembedded ovarian carcinoma tissues were used for histological evaluation. All haematoxylin and eosin ( $\mathrm{H} \& \mathrm{E}$ )-stained sections were reviewed by gynaecological pathologists. The study was approved by the Institutional Review Board.

\section{Western blot analysis}

Protein concentrations were measured with the Bradford protein assay before analysis. Total cell lysate ( $30 \mu \mathrm{g}$ of protein) was separated by SDS-polyacrylamide gel electrophoresis and subjected to western blot analysis. Anti-BubR1 antibody (BD, San Jose, CA, USA) was used at a dilution of $1: 1000$ and anti-Aurora A antibody (Transgenic, Japan) at a dilution of $1: 300$.

\section{Immunofluorescence analysis}

Cells grown on cover slips were fixed with $4 \%$ paraformaldehyde, then permeabilised with $0.5 \%$ Triton X-100 phosphate-buffered saline $(0.5 \%$ PBS-T $)$. They were then incubated in blocking solution $(20 \%$ goat serum in $0.1 \%$ PBS-T) and probed with anti-BubR1 antibody or anti-Aurora A antibodies. The cells were mounted with Vectashield containing 4',6-diamino-2-phenylindole (DAPI) (Vector Laboratories, Burlingame, CA, USA). Images were acquired on the DeltaVision microscope (Applied Precision, Seattle, WA, USA) as a series of $0.4-\mu$ m-thick sections and merged.

\section{Cytogenic analysis}

Spreads of metaphases were described previously with slight modifications (Patel et al, 1998; Lee et al, 1999).

\section{Immunohistochemical analysis}

Paraffin blocks from ovarian carcinoma were cut at $4 \mu \mathrm{m}$ adjacent to H \& E sections. Samples were deparaffinised in xylene, rehydrated with graded ethanol, and washed in distilled water. The sections were then placed in $10 \mathrm{~mm}$ citrate buffer $(\mathrm{pH}$ 6.0) and boiled in a microwave for epitope retrieval. Endogenous peroxidase activity was quenched by incubating tissue sections in $3 \% \mathrm{H}_{2} \mathrm{O}_{2}$ for $10 \mathrm{~min}$. After the blocking procedure with $20 \%$ goat serum and $1 \%$ bovine serum albumin (BSA) in PBS at room temperature for $1 \mathrm{~h}$, sections were incubated with a primary antibody against BubR1 (mouse monoclonal, BD) at a dilution of $1: 300$ or Aurora A (rabbit polyclonal,
Transgenic) at a dilution of $1: 250$ in a humidifying chamber at $4{ }^{\circ} \mathrm{C}$ overnight. They were then washed in PBS for $5 \mathrm{~min}$ at room temperature, subsequently stained by the labelled streptavidin biotin (LSAB) method using a Dako LSAB kit (Dako, Glostrup, Denmark), and visualised using 3,3'-diaminobenzidine. The sections were then counterstained with haematoxylin.

To check the nuclear staining of Aurora A, antigen retrieval in $20 \mathrm{~mm}$ Tris-EDTA buffer ( $\mathrm{pH}$ 9.0) was also performed in 80 samples using antibodies from Novocastra (NCL-L-AK2, New Castle, UK) at a dilution of $1: 50$ and following the methods of Burum-Auensen et al (Burum-Auensen et al, 2007a). The results were similar to the antigen retrieval procedure using citrate ( $\mathrm{pH}$ 6.0) and Tris-EDTA ( $\mathrm{pH}$ 9.0) buffer described above (Supplementary Figure). Slides were subjected to the same staining procedure without the addition of primary antibodies for negative controls. Microscopic fields from each stained section were randomly sampled.

In most cases, BubR1 and Aurora A were stained in the cytoplasm in interphase. However, a few specimens revealed nuclear staining of Aurora A, especially when Tris-EDTA buffer ( $\mathrm{pH}$ 9.0) was used. The percentage of positive staining distribution was recorded and scored as follows: a score of 0 for staining $<5 \%$, 1 for $6-25 \%$ staining, 2 for $26-50 \%$ staining, 3 for $51-75 \%$ staining, and 4 for staining $>75 \%$. The staining intensity was scored as follows: a score of 0 for absent tumour cell staining, 1 for weak staining (equivocal to normal epithelium), 2 for moderate staining, and 3 for strong staining. For BubR1 and Aurora A, the results for intensity and distribution were summed and total score was assigned as follows: sum of $0-1$, score 0 ; sum of $2-3$, score 1 ; sum of $4-5$, score 2 ; sum of $6-7$, score 3 .

\section{Statistical analysis}

The relationships between categorical variables were assessed using the $\chi^{2}$ test. Recurrence-free survival (RFS) was estimated using the Kaplan-Meier method, and the differences in survival were compared using the log-rank test. Multivariate analysis was carried out using the Cox regression method. A $P$-value of $<0.05$ was considered to be statistically significant. Data were analysed using SPSS software, version 12.0 (SPSS Inc., Chicago, IL, USA).

\section{RESULTS}

\section{Aberrant BubR1 and Aurora A levels and subcellular localisations in ovarian cancer cells}

We used western analysis to determine whether the two proteins are expressed in OVCAR3, SK-OV-3, and SNU119 ovarian cancer cells. The results show that all three cancer cell lines, which were randomly picked, express BubR1 and Aurora A to varying degrees (Figure 1A). As accurate mitosis is guaranteed by the proper localisation of BubR1 at kinetochores and of Aurora A at centrosomes, we examined the levels and localisation of BubR1 and Aurora A by immunofluorescence microscopy. As revealed in Figure 1B, all three cell lines analysed displayed defective Aurora A or BubR1 immunostaining at appropriate locations. Furthermore, the patterns of BubR1 and Aurora A staining were heterogeneous from cell to cell in the same cell line (data not shown).

Chromosome instability is accompanied by a heterogeneity of chromosome numbers in individual cells. Therefore, cytogenetic analysis of a statistically significant number of cells is the most direct measure of assessing aneuploidy. To confirm that these three cell lines exhibit CIN, we analysed metaphase chromosome spreads of 10 different cells from each line. The number of chromosomes in all cancer cell lines (OVCAR3, SK-OV-3, and SNU119) was highly variable in 10 different metaphase chromosome spreads (Figure $1 \mathrm{C}$ ). This result is consistent with information available from the American Culture Type Collection. 
A

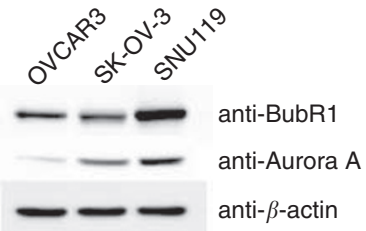

B

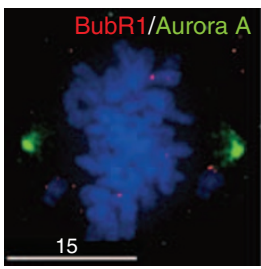

OVCAR3

C

\begin{tabular}{lccc}
\hline \multirow{2}{*}{$\begin{array}{l}\text { No. of } \\
\text { chromosomes }\end{array}$} & \multicolumn{3}{c}{ No. of cells } \\
\cline { 2 - 4 } & OVCAR3 & SK-OV-3 & SNU119 \\
\hline$<35$ & 2 & 2 & 2 \\
$35-43$ & 0 & 1 & 0 \\
$44-48$ & 1 & 1 & 0 \\
$49-55$ & 2 & 3 & 2 \\
$>55$ & 5 & 3 & 6 \\
\hline
\end{tabular}

D

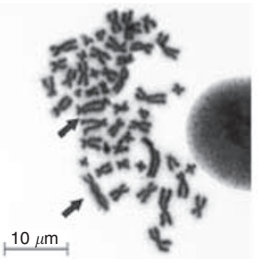

OVCAR3

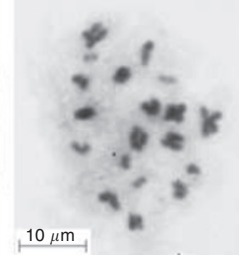

SK-OV-3

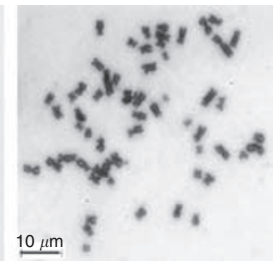

SNU119

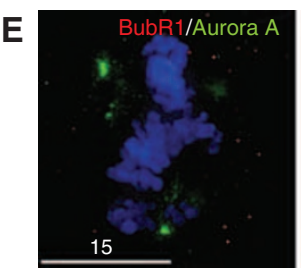

Ov_ca_01

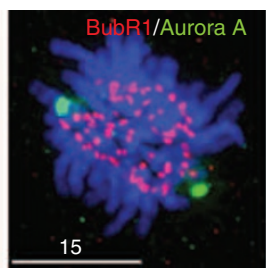

Ov_ca_02

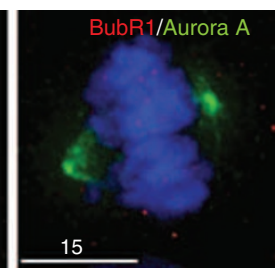

Ov_ca_03
Figure I Assessing BubRI and Aurora A levels and localisation in ovarian cancer cells. (A) Western blot analysis of ovarian cancer cell lines, OVCAR3, SK-OV-3, and SNUI19, using anti-BubRI and Aurora A antibodies. (B) Immunofluorescence analysis of ovarian cancer cell lines (OVCAR3, SK-OV-3, and SNUI 19). Cells grown on cover slips were fixed and immunostained with anti-BubRI (red) and anti-Aurora A (green) antibodies. DAPI (blue) staining reveals chromosomes. (C) Cytogenic analysis of ovarian cancer cell lines. Ten different metaphase chromosome spreads were analysed for their chromosome number. All three ovarian cancer cell lines are aneuploid. Diploid cells should have 46 chromosomes. (D) Representative metaphase chromosome spreads showing chromosome number aberrations in the three cell lines analysed. In OVCAR3, chromosome fusions, another important measure of CIN, were observed in OVCAR3 and are marked as arrows. Scale bars are marked. (E) Immunofluorescence analysis of three primary ovarian cancer cells (Ov_ca_0I, Ov_ca_02, and Ov_ca_03). Images were taken and processed on a DeltaVision RT (Applied Precision) with $\times 1000$ magnification. White scale bars $15 \mu \mathrm{m}$.

A representative chromosome spread revealed that one of the cell lines analysed, OVCAR3, exhibited aberrant chromosome fusions, as well as aneuploidy (Figure 1D).

As immunofluorescence assay (IFA) in ovarian cancer cell lines depicted a varying degree of BubR1 or Aurora A levels and
Table I Clinicopathological characteristics of ovarian cancer patients

\begin{tabular}{lc}
\hline & Number of patients (\%) \\
\hline Median age (year, range) & $51.5(18-79)$ \\
FIGO stage & $43(26.9)$ \\
I & $13(8.1)$ \\
III & $86(53.8)$ \\
IV & $18(11.2)$ \\
Histology & \\
Serous & \\
Mucinous & $92(57.5)$ \\
Endometrioid & $24(15.0)$ \\
Clear cell & $23(14.4)$ \\
Others & $18(11.2)$ \\
& $3(1.9)$ \\
Grade & \\
I & \\
2 & $27(16.9)$ \\
3 & $43(26.9)$ \\
& $90(56.2)$ \\
Residual tumour & \\
Residual tumour $\leqslant$ I cm & \\
Residual tumour $>$ I cm & $83(51.9)$ \\
Clinical response & $77(48.1)$ \\
Complete response & \\
Partial response & $111(69.4)$ \\
Stable disease & $16(10.0)$ \\
Progressive disease & $15(9.4)$ \\
\hline
\end{tabular}

Table 2 Score of BubRI and Aurora A levels in ovarian tissue samples

\begin{tabular}{lcclccc}
\hline & \multicolumn{2}{c}{ Ovarian cancer $(\boldsymbol{n}=\mathbf{I 6 0})$} & & \multicolumn{2}{c}{ Normal ovary $(\boldsymbol{n}=\mathbf{I 0})$} \\
\cline { 2 - 3 } \cline { 6 - 7 } & BubRI (\%) & Aurora A (\%) & & BubRI (\%) & Aurora A (\%) \\
\hline Score 0 & $39(24.4)$ & $45(28.1)$ & & $10(100.0)$ & $10(100.0)$ \\
Score 1 & $60(37.5)$ & $63(39.4)$ & & 0 & 0 \\
Score 2 & $42(26.3)$ & $36(22.5)$ & & 0 & 0 \\
Score 3 & $19(11.9)$ & $16(10.0)$ & & 0 & 0 \\
\hline
\end{tabular}

subcellular localisation in mitosis (Figure 1B), we next asked whether primary tumour cells exhibit similar results. The result showed that the primary tumour cells also displayed mislocalisations and heterogeneity of BubR1 or Aurora A levels in IFA (Figure 1E).

\section{Correlation of BubR1 and Aurora A levels and patient survival}

Immunohistochemistry staining was conducted on 170 paraffinembedded samples: 160 ovarian cancer and 10 normal ovary tissues. The age of cancer patients ranged from 18 to 79 years (median, 51.5 years). Table 1 describes the clinicopathological characteristics of 160 cancer patients. Except for 10 patients, all the cancer patients were at stage Ic or higher and hence underwent primary debulking surgery, followed by taxane and platinum chemotherapy. Serous cystadenocarcinoma $(57.5 \%)$ was the most common histology. Cytoreductive surgery was optimal $(\leqslant 1 \mathrm{~cm}$ residual disease) in 51.9\%. More than two-thirds of patients had a complete response to first-line treatment, yet half of them relapsed (Table 1).

Of the 160 ovarian cancer samples, a quarter of them $(24.2 \%)$ were scored 0 for BubR1 immunostaining and about $30 \%$ scored 0 for Aurora A, whereas normal specimens scored 0 in all cases (Table 2, Figure 2). The relationship between levels of BubR1 and the clinicopathological parameters of 160 tumours is shown in 
A

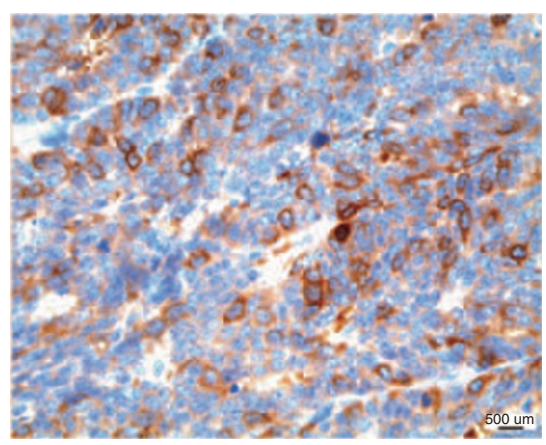

BubR1 (+)

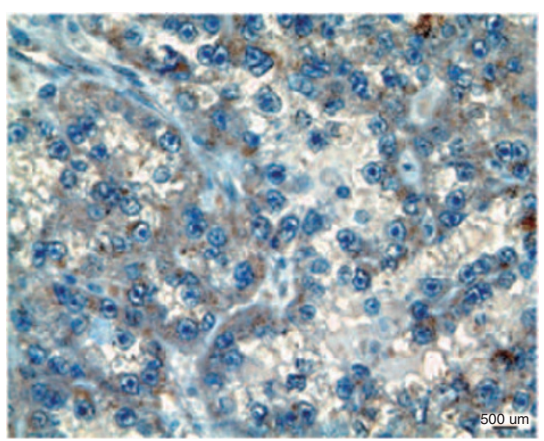

Aurora $\mathrm{A}(+)$

B

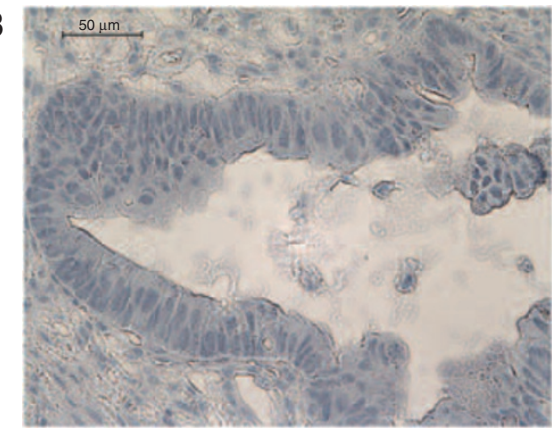

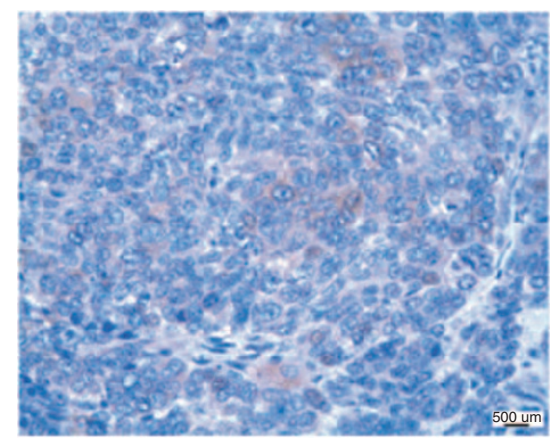

BubR1 (-)

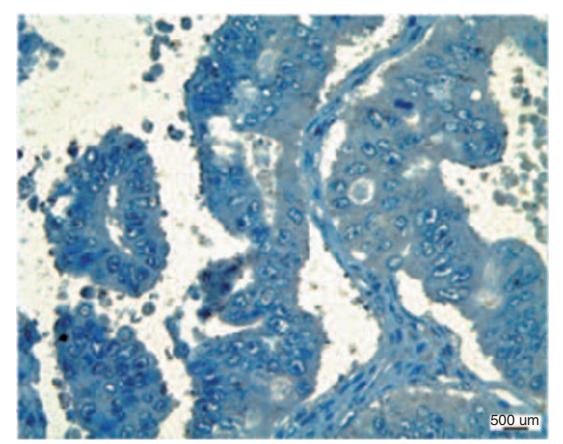

Aurora A (-)

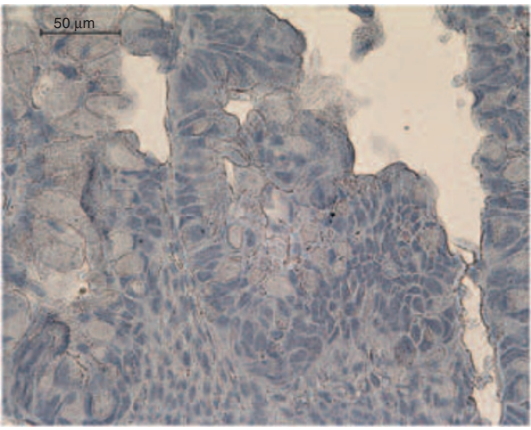

Figure 2 Immunohistochemical staining of BubRI and Aurora A (A) Representative positive and negative immunohistochemistry images of BubRI and Aurora A in paraffin-embedded human cancer samples (magnification $\times 400$ ). (B) Negative controls for antibody staining. Antigens were retrieved with Tris-EDTA buffer at $\mathrm{pH}$ 9.0. $\mathrm{HC}$ was performed without incubation with primary antibodies. Two examples are shown (magnification $\times 400)$. Images were taken on an Olympus BX-5I microscope.

Table 3. Positive BubR1 expression was associated with advanced stage $(P=0.001)$, serous histology $(P=0.008)$, high grade $(P=0.001)$, and residual tumour $(P=0.021)$. In contrast, no significant correlation was observed between the expression of BubR1 and Aurora A. In univariate survival analysis, BubR1 immunoreactivity was a significant prognostic factor for RFS $(P<0.001)$, whereas the Aurora A expression was not $(P=0.633)$. Patients with immunoreactive BubR1 (score 1, 2,3) had a median RFS of 27 months (range, 3-48 months), whereas those with a negative expression of BubR1 (score 0) had a median RFS of 83 months (range, 2-115 months). Figure 3 shows survival curves stratified by BubR 1 and Aurora A expression. Multivariate survival analysis (Table 4) indicated that the BubR1 level was an independent prognostic factor for predicting recurrence of ovarian cancer patients.

\section{DISCUSSION}

Strategies in the treatment of ovarian cancers are mainly determined by the degree of tumour differentiation, the FIGO stage of disease, and the volume of residual disease after surgery. However, owing to a significant degree of tumour heterogeneity, even in the same prognostic subgroup, the development of new prognostic markers that can aid in selecting adequate therapy for individual patients is essential. In this vein, it should be emphasised that the mechanisms underlying the development of each cancer vary, and a consideration of the mechanistic parameters mirroring the different molecular pathways is required for tailored cancer therapy.

We have confirmed that CIN is prevalent in ovarian cancer cell lines (Figure 1), consistent with the notion that taxane, the microtubule poison, has factored to a large extent in the treatment of ovarian cancers. As the mutations in SAC genes are rare (Cahill et al, 1998; Imai et al, 1999; Haruki et al, 2001; Hernando et al, 2001; Olesen et al, 2001; Langerod et al, 2003; Yuan et al, 2006), it seems that examining the levels of SAC proteins may be more informative. Furthermore, despite the incidence of CIN in ovarian cancers, the status of SAC proteins such as Bub1, Mad2, Mad1, and BubR1 had not been satisfactorily addressed (Lee et al, 2004; Fu et al, 2007). With these notions, we analysed the levels of BubR1 and Aurora A in 170 specimens for their clinical significance. The 
results showed a striking correlation between BubR1 levels and RFS. Moreover, a high level of BubR1 was associated with several aggressive clinicopathological parameters. These data imply the possibility that BubR1 may be related to the progression of epithelial ovarian cancers. Related to our study, an overexpression of BubR1 has been observed in several human cancers, including breast, gastric, bladder, kidney, and colorectal carcinomas (Myrie et al, 2000; Shichiri et al, 2002; Grabsch et al, 2003; Yamamoto et al, 2007; Pinto et al, 2008). In addition, it has been reported that the overall pattern of BubR1 localisation, revealed by immunostaining, differed between normal and malignant tissues in bladder, colon, pancreas, and skin cancers (Shin et al, 2003; Yamamoto et al, 2007; Burum-Auensen et al, 2007b).

Functional BubR1 is crucial for dividing cells, but not for quiescent cells. Therefore, our results showing that BubR1 elevation is correlated with poor prognosis, cancer aggression, and RFS may reflect the proliferative capacity of tumour cells. It is

Table 3 Correlation of BubRI level and clinicopathological parameters

\begin{tabular}{|c|c|c|c|c|}
\hline & \multirow[b]{2}{*}{ Number of patients } & \multicolumn{2}{|c|}{ BubRI expression } & \multirow[b]{2}{*}{$P$-value } \\
\hline & & Negative & Positive & \\
\hline \multicolumn{5}{|l|}{ Age } \\
\hline$<55$ years & 97 & 28 & 69 & 0.016 \\
\hline$\geqslant 55$ years & 63 & II & 52 & \\
\hline \multicolumn{5}{|l|}{ FIGO stage } \\
\hline Early (I, II) & 56 & 26 & 30 & 0.001 \\
\hline Advanced (III, IV) & 104 & 13 & 91 & \\
\hline \multicolumn{5}{|l|}{ Histology } \\
\hline Serous & 92 & 13 & 79 & 0.008 \\
\hline Non-serous & 68 & 26 & 42 & \\
\hline \multicolumn{5}{|l|}{ Grade } \\
\hline I & 27 & 16 & 11 & 0.001 \\
\hline 2 and 3 & 133 & 23 & 110 & \\
\hline \multicolumn{5}{|l|}{ Residual tumour } \\
\hline$\leqslant 1 \mathrm{~cm}$ & 83 & 32 & 51 & 0.021 \\
\hline$>1 \mathrm{~cm}$ & 77 & 7 & 70 & \\
\hline
\end{tabular}

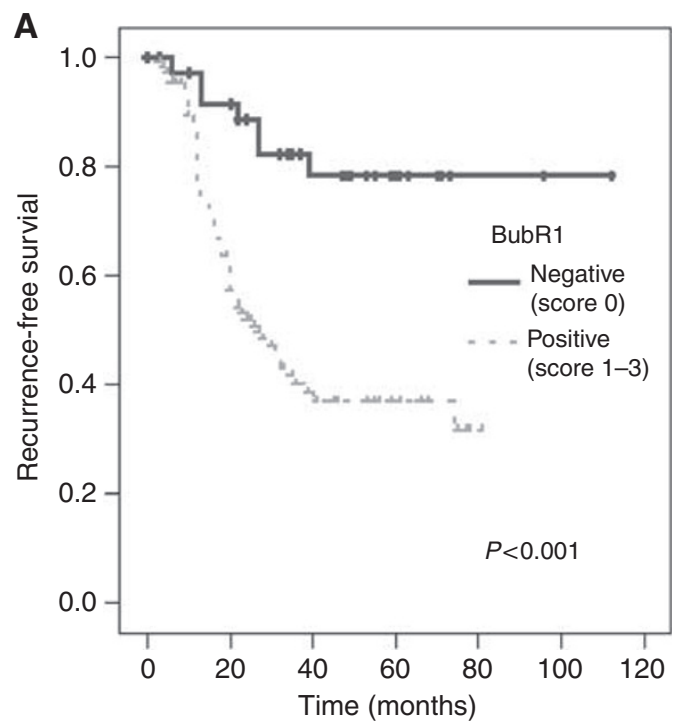

very likely that the expression of BubR1 is elevated in cycling cells (Burum-Auensen et al, 2007b). Therefore, we speculate that the elevated level of BubR1 coincides with a high mitotic index. We do not think that BubR1 elevation initiates tumourigenesis. Instead, we speculate that mutations in genes responsible for proliferative cell signaling or in tumour suppressor genes such as BRCA1, $B R C A 2$, and $p 53$ are likely to take place before the elevation of BubR1 levels. Continued proliferation will make the cells susceptible to a high mutation rate, accompanied by massive cell death. Surviving cells are likely to have higher levels of BubR1 owing to forced proliferation, and at the same time acquire genetic instability because of accumulated mutations. This will accelerate the heterogeneity of the tumour, resulting in resistance to conventional cancer therapy.

Table 4 Univariate and multivariate analysis of prognostic factors in ovarian cancer patients for recurrence-free survival

\begin{tabular}{|c|c|c|c|}
\hline & \multirow{2}{*}{$\begin{array}{c}\begin{array}{c}\text { Univariate } \\
\text { analysis }\end{array} \\
\text { P-value }\end{array}$} & \multicolumn{2}{|c|}{$\begin{array}{c}\text { Multivariate } \\
\text { analysis }\end{array}$} \\
\hline & & $P$-value & $\operatorname{RR}(95 \% \mathrm{Cl})$ \\
\hline Age & & & \\
\hline $\begin{array}{l}<55 \text { years vs } \geqslant 55 \\
\text { years }\end{array}$ & 0.153 & 0.134 & $1.506(0.085-2.261)$ \\
\hline $\begin{array}{l}\text { FIGO stage } \\
\text { Early (I, II) vs } \\
\text { advanced (III, IV) }\end{array}$ & $<0.001$ & 0.001 & $4.375(2.920-6.555)$ \\
\hline $\begin{array}{l}\text { Histology } \\
\text { Serous vs non-serous }\end{array}$ & $<0.001$ & 0.045 & $0.363(0.240-0.549)$ \\
\hline $\begin{array}{l}\text { Grade } \\
\quad 1 \text { vs } 2 \text { and } 3\end{array}$ & 0.004 & 0.012 & $2.269(1.686-3.053)$ \\
\hline $\begin{array}{l}\text { Residual tumour } \\
\quad \leqslant 1 \mathrm{~cm} \text { vs }>1 \mathrm{~cm}\end{array}$ & $<0.001$ & 0.006 & $3.197(1.905-5.364)$ \\
\hline $\begin{array}{l}\text { BubRI expression } \\
\text { Negative vs positive }\end{array}$ & $<0.001$ & 0.035 & $1.929(1.400-2.656)$ \\
\hline
\end{tabular}

$\mathrm{Cl}=$ confidence interval; $\mathrm{RR}=$ relative risk.

B

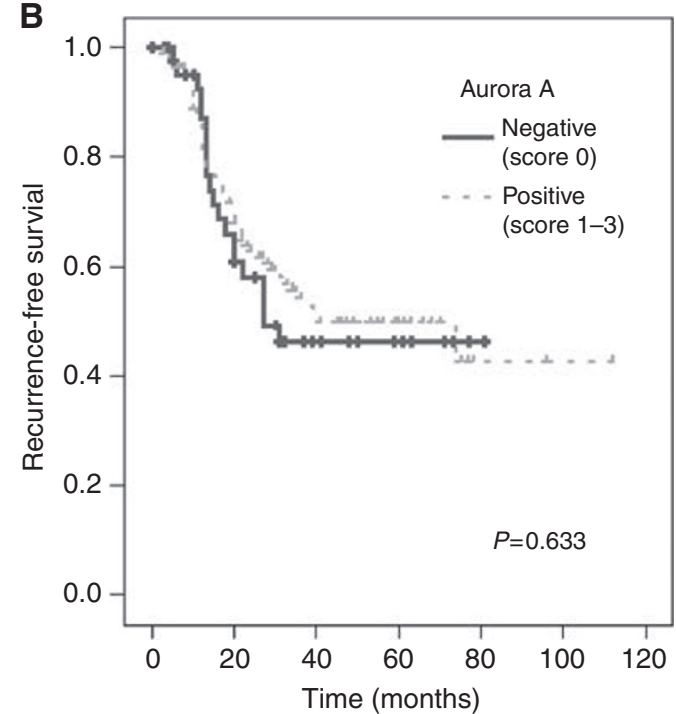

Figure 3 Recurrence-free survival (RFS) using the Kaplan-Meier method in relation to BubRI and Aurora A levels. (A) BubRI positive immunostaining in the tumour had poor RFS compared with negative staining $(P<0.00 \mathrm{I})$. (B) Aurora A scores did not show significant correlation with RFS. 
Our finding that Aurora A is not a prognostic factor in ovarian cancers contradicts the report that amplification of Aurora A has been observed in many human cancers. Despite reports that the overexpression of Aurora A in Rat1 or NIH3T3 cells induces transformation (Bischoff et al, 1998; Zhou et al, 1998), transgenic mice overexpressing Aurora A (Zhang et al, 2004) or the overexpression of Aurora A in normal fibroblasts (Anand et al, 2003) does not induce neoplastic transformation. These seemingly contradictory results may come from the fact that the immortalised cell lines, such as Rat1 or NIH3T3, used by Bischoff et al (1998) and Zhou et al (1998), already harbour mutations and are, therefore, easier to transform. By comparison, Aurora A overexpression does not induce tumourigenesis in primary fibroblasts and mice. Thus, our results may correlate with the notion that amplification of Aurora A may result in CIN, whereas overexpression by itself does not initiate neoplastic transformation (Giet et al, 2005). Similarly, BubR1 amplification does not initiate tumourigenesis, and its amplification has not been reported in human cancers.

In conclusion, we suggest that BubR1 is a reliable prognostic marker for predicting RFS after initial treatment, and that assessing the levels of BubR1 in early-stage ovarian cancer patients, especially with FIGO I stage, can influence the choice of

\section{REFERENCES}

Abrieu A, Kahana JA, Wood KW, Cleveland DW (2000) CENP-E as an essential component of the mitotic checkpoint in vitro. Cell 102: 817-826 Amon A (1999) The spindle checkpoint. Curr Opin Genet Dev 9: 69-75

Anand S, Penrhyn-Lowe S, Venkitaraman AR (2003) AURORA-A amplification overrides the mitotic spindle assembly checkpoint, inducing resistance to Taxol. Cancer Cell 3: 51-62

Berdnik D, Knoblich JA (2002) Drosophila Aurora-A is required for centrosome maturation and actin-dependent asymmetric protein localization during mitosis. Curr Biol 12: 640-647

Bischoff JR, Anderson L, Zhu Y, Mossie K, Ng L, Souza B, Schryver B, Flanagan P, Clairvoyant F, Ginther C, Chan CS, Novotny M, Slamon DJ, Plowman GD (1998) A homologue of Drosophila aurora kinase is oncogenic and amplified in human colorectal cancers. EMBO J 17: $3052-3065$

Burum-Auensen E, De Angelis PM, Schjolberg AR, Kravik KL, Aure M, Clausen OP (2007a) Subcellular localization of the spindle proteins Aurora A, Mad2, and BUBR1 assessed by immunohistochemistry. J Histochem Cytochem 55: 477-486

Burum-Auensen E, Deangelis PM, Schjolberg AR, Roislien J, Andersen SN, Clausen OP (2007b) Spindle proteins Aurora A and BUB1B, but not Mad2, are aberrantly expressed in dysplastic mucosa of patients with longstanding ulcerative colitis. J Clin Pathol 60: 1403-1408

But I, Gorisek B (2000) DNA-ploidy as an independent prognostic factor in patients with serous ovarian carcinoma. Int J Gynaecol Obstet 71: $259-262$

Cahill DP, Lengauer C, Yu J, Riggins GJ, Willson JK, Markowitz SD, Kinzler KW, Vogelstein B (1998) Mutations of mitotic checkpoint genes in human cancers. Nature 392: $300-303$

Chan GK, Yen TJ (2003) The mitotic checkpoint: a signaling pathway that allows a single unattached kinetochore to inhibit mitotic exit. Prog Cell cycle Res 5: 431-439

Choi E, Choe H, Min J, Choi JY, Kim J, Lee H (2009) BubR1 acetylation at prometaphase is required for modulating APC/C activity and timing of mitosis. EMBO J e-pub ahead 30 April 2009; doi:10.1038/emboj.2009.123

Chi YH, Jeang KT (2007) Aneuploidy and cancer. J Cell Biochem 102: $531-538$

Elowe S, Hummer S, Uldschmid A, Li X, Nigg EA (2007) Tension-sensitive Plk1 phosphorylation on BubR1 regulates the stability of kinetochore microtubule interactions. Genes Dev 21: 2205-2219

Friedlander ML (1998) Prognostic factors in ovarian cancer. Semin Oncol 25: $305-314$

Fu Y, Ye D, Chen H, Lu W, Ye F, Xie X (2007) Weakened spindle checkpoint with reduced BubR1 expression in paclitaxel-resistant ovarian carcinoma cell line SKOV3-TR30. Gynecol Oncol 105: 66-73

Giet R, Petretti C, Prigent C (2005) Aurora kinases, aneuploidy and cancer, a coincidence or a real link? Trends Cell Biol 15: 241-250 adequate treatment for ovarian cancers. Furthermore, modulating BubR1 activity may be a promising future approach to tailored therapy for ovarian cancers.

\section{ACKNOWLEDGEMENTS}

Research in the $\mathrm{H}$ Lee laboratory is funded by the National Research Laboratory Program from the Korean ministry of Education and Science (ROA-2008-000-20023-0). This work was also supported by the Seoul National University Hospital Grant (0420080450), the 21C Frontier Functional Genome Project (FG062-14) of the Korean ministry of Education and Science, Korea Research Foundation (KRF-2005-C00097), and the National R\&D Program for Cancer Control (0620070) from the Korean ministry of Health welfare and Family Affairs. Imaging facilities in the $\mathrm{H}$ Lee laboratory are funded by RCFC (R11-2005-009-04003-0) of the SRC program from KOSEF.

Supplementary Information accompanies the paper on British Journal of Cancer website (http://www.nature.com/bjc)

Gorringe KL, Chin SF, Pharoah P, Staines JM, Oliveira C, Edwards PA, Caldas C (2005) Evidence that both genetic instability and selection contribute to the accumulation of chromosome alterations in cancer. Carcinogenesis 26: $923-930$

Grabsch H, Takeno S, Parsons WJ, Pomjanski N, Boecking A, Gabbert HE, Mueller W (2003) Overexpression of the mitotic checkpoint genes BUB1, BUBR1, and BUB3 in gastric cancer-association with tumour cell proliferation. J Pathol 200: 16-22

Hannak E, Kirkham M, Hyman AA, Oegema K (2001) Aurora-A kinase is required for centrosome maturation in Caenorhabditis elegans. J Cell Biol 155: 1109-1116

Haruki N, Saito H, Harano T, Nomoto S, Takahashi T, Osada H, Fujii Y (2001) Molecular analysis of the mitotic checkpoint genes BUB1, BUBR1 and BUB3 in human lung cancers. Cancer Lett 162: 201-205

Hernando E, Orlow I, Liberal V, Nohales G, Benezra R, CordonCardo C (2001) Molecular analyses of the mitotic checkpoint components hsMAD2, hBUB1 and hBUB3 in human cancer. Int J Cancer 95: $223-227$

Imai Y, Shiratori Y, Kato N, Inoue T, Omata M (1999) Mutational inactivation of mitotic checkpoint genes, hsMAD2 and hBUB1, is rare in sporadic digestive tract cancers. Jpn J Cancer Res 90: 837-840

Jemal A, Siegel R, Ward E, Murray T, Xu J, Thun MJ (2007) Cancer statistics, 2007. CA Cancer J Clin 57: 43-66

Kristensen GB, Trope C (1997) Epithelial ovarian carcinoma. Lancet 349: $113-117$

Lampson MA, Kapoor TM (2005) The human mitotic checkpoint protein BubR1 regulates chromosome-spindle attachments. Nat Cell Biol 7: $93-98$

Langerod A, Stromberg M, Chin K, Kristensen VN, Borresen-Dale AL (2003) BUB1 infrequently mutated in human breast carcinomas. Hum Mutat 22: 420

Lee EA, Keutmann MK, Dowling ML, Harris E, Chan G, Kao GD (2004) Inactivation of the mitotic checkpoint as a determinant of the efficacy of microtubule-targeted drugs in killing human cancer cells. Mol Cancer Ther 3: $661-669$

Lee H, Trainer AH, Friedman LS, Thistlethwaite FC, Evans MJ, Ponder BA, Venkitaraman AR (1999) Mitotic checkpoint inactivation fosters transformation in cells lacking the breast cancer susceptibility gene, Brca2. Mol Cell 4: 1-10

Myrie KA, Percy MJ, Azim JN, Neeley CK, Petty EM (2000) Mutation and expression analysis of human BUB1 and BUB1B in aneuploid breast cancer cell lines. Cancer Lett 152: 193-199

Nigg EA (2002) Centrosome aberrations: cause or consequence of cancer progression? Nat Rev Cancer 2: 815-825

Nigg EA (2006) Origins and consequences of centrosome aberrations in human cancers. Int J Cancer 119: 2717-2723 
NIH consensus conference (1995) Ovarian cancer. Screening, treatment, and follow-up. NIH Consensus Development Panel on Ovarian Cancer. JAMA 273: $491-497$

Olesen SH, Thykjaer T, Orntoft TF (2001) Mitotic checkpoint genes hBUB1, hBUB1B, hBUB3 and TTK in human bladder cancer, screening for mutations and loss of heterozygosity. Carcinogenesis 22: $813-815$

Patel KJ, Yu VP, Lee H, Corcoran A, Thistlethwaite FC, Evans MJ, Colledge WH, Friedman LS, Ponder BA, Venkitaraman AR (1998) Involvement of Brca2 in DNA repair. Mol Cell 1: $347-357$

Pinto M, Vieira J, Ribeiro FR, Soares MJ, Henrique R, Oliveira J, Jeronimo C, Teixeira MR (2008) Overexpression of the mitotic checkpoint genes BUB1 and BUBR1 is associated with genomic complexity in clear cell kidney carcinomas. Cell Oncol 30: 389-395

Sen S (2000) Aneuploidy and cancer. Curr Opin Oncol 12: $82-88$

Sen S, Katayama H, Sasai K (2008) Functional significance of Aurora kinase $\mathrm{A}$ in centrosome amplification and genomic instability. Adv Exp Med Biol 617: $99-108$

Sen S, Zhou H, Zhang RD, Yoon DS, Vakar-Lopez F, Ito S, Jiang F, Johnston D, Grossman HB, Ruifrok AC, Katz RL, Brinkley W, Czerniak B (2002) Amplification/overexpression of a mitotic kinase gene in human bladder cancer. J Natl Cancer Inst 94: 1320-1329

Shichiri M, Yoshinaga K, Hisatomi H, Sugihara K, Hirata Y (2002) Genetic and epigenetic inactivation of mitotic checkpoint genes hBUB1 and hBUBR1 and their relationship to survival. Cancer Res 62: 13-17

Shin HJ, Baek KH, Jeon AH, Park MT, Lee SJ, Kang CM, Lee HS, Yoo SH, Chung DH, Sung YC, McKeon F, Lee CW (2003) Dual roles of human BubR1, a mitotic checkpoint kinase, in the monitoring of chromosomal instability. Cancer Cell 4: 483-497
Shridhar V, Lee J, Pandita A, Iturria S, Avula R, Staub J, Morrissey M, Calhoun E, Sen A, Kalli K, Keeney G, Roche P, Cliby W, Lu K, Schmandt R, Mills GB, Bast Jr RC., James CD, Couch FJ, Hartmann LC, Lillie J, Smith DI (2001) Genetic analysis of early- versus late-stage ovarian tumors. Cancer Res 61: 5895-5904

Tang Z, Bharadwaj R, Li B, Yu H (2001) Mad2-independent inhibition of APCCdc20 by the mitotic checkpoint protein BubR1. Dev Cell 1: 227-237

Tong T, Zhong Y, Kong J, Dong L, Song Y, Fu M, Liu Z, Wang M, Guo L, Lu S, Wu M, Zhan Q (2004) Overexpression of Aurora-A contributes to malignant development of human esophageal squamous cell carcinoma. Clin Cancer Res 10: 7304-7310

Yamamoto Y, Matsuyama H, Chochi Y, Okuda M, Kawauchi S, Inoue R, Furuya T, Oga A, Naito K, Sasaki K (2007) Overexpression of BUBR1 is associated with chromosomal instability in bladder cancer. Cancer Genet Cytogenet 174: $42-47$

$\mathrm{Yu} \mathrm{H}$ (2002) Regulation of APC-Cdc20 by the spindle checkpoint. Curr Opin Cell Biol 14: $706-714$

Yuan B, Xu Y, Woo JH, Wang Y, Bae YK, Yoon DS, Wersto RP, Tully E, Wilsbach K, Gabrielson E (2006) Increased expression of mitotic checkpoint genes in breast cancer cells with chromosomal instability. Clin Cancer Res 12: $405-410$

Zhang D, Hirota T, Marumoto T, Shimizu M, Kunitoku N, Sasayama T, Arima Y, Feng L, Suzuki M, Takeya M, Saya H (2004) Cre-loxPcontrolled periodic Aurora-A overexpression induces mitotic abnormalities and hyperplasia in mammary glands of mouse models. Oncogene 23: $8720-8730$

Zhou H, Kuang J, Zhong L, Kuo WL, Gray JW, Sahin A, Brinkley BR, Sen S (1998) Tumour amplified kinase STK15/BTAK induces centrosome amplification, aneuploidy and transformation. Nat Genet 20: 189-193 